\title{
İnflamatuvar barsak hastalarında vedolizumab deneyimi: Tek merkez verileri
}

\author{
Vedolizumab experience in patients with inflammatory bowel disease: Single center data
}

\author{
(D)Ayça Gökçen DEĞiRMENCI SALTÜRK \\ Haydarpaşa Numune Eğitim ve Araştırma Hastanesi Gastroenteroloji Kliniği, İstanbul
}

\begin{abstract}
Giriş ve Amaç: Vedolizumab, orta ve ağır aktiviteli inflamatuvar barsak hastalıklarının tedavisinde kullanılan $\alpha 4 \beta 7$ integrindir. Tümör nekroz faktör antagonisti ilaçlar ile tedavi başarısı sağlanamamış inflamatuvar barsak hastalarında tercih edilmektedir. Çalısmamızda tümör nekroz faktör antagonistine cevapsız, komplike hasta gruplarında tek merkez verileriyle vedolizumab tedavisinin 12. aydaki etkinliğini ve güvenirliğini araştırdık. Gereç ve Yöntem: Ocak 2019- Eylül 2020 tarihleri arasında Haydarpaşa Numune Eğitim ve Araştırma Hastanesi Gastroenteroloji Kliniğine başvuran 6 aydan uzun vedolizumab tedavisi almış tümör nekroz faktör antagonisti deneyimli hastalar çalışmaya dahil edilmiştir. Vedolizumab tedavisi öncesi ve 12. ayda endoskopik remisyon kaydedildimiştir. Bulgular: Tüm hastaların 17'si (\%48.5) kadındı. Yaş ortalaması $43 \pm$ 13'tü (22-76). Bu hastalardan 23'ü Crohn hastası ve 12'si ülseratif kolit hastasıydı. Crohn hastalarının 15'inde (\%65.2) endoskopik remisyon sağlanırken, 8 hasta (\%34.78) cevapsız kabul edildi. Ülseratif kolitte ise endoskopik remisyon ve cevapsız hasta sayısı eşitti $(n=6, \% 50)$. Sonuç: Çalışmamızda, tümör nekroz faktör antagonisti deneyimli hastalarda, özellikle Crohn hastaları olmak üzere inflamatuvar barsak hastalarında vedolizumab kullanımının etkin ve güvenilir olduğu gözlemlenmiştir.
\end{abstract}

Anahtar kelimeler: Crohn hastalığı, ülseratif kolit, vedolizumab

\section{GíRiş}

Inflamatuvar barsak hastalığında (IBH) [Crohn hastalığı $(\mathrm{CH})$ ve ülseratif kolit hastalığı (ÜK)] tedavinin amacı kalıc klinik, mukozal ve histolojik iyileşmenin sağlanmasıdır (1). Konvansiyonel tedaviler, tedavi yetersizliğinin olması (aminosalisilatlar) veya yan etki profillerinin yüksek olması (kortikosteroidler/azatiopürin/metotreksat/6-merkaptopürin) nedeniyle biyolojik ilaçların kullanılma ihtiyacını doğurmuştur (2). Ülkemizde orta ve şiddetli İBH hastalarında biyolojik ajan olarak tümör nekroz faktör antagonistlerinin (anti-TNF) ilk tedavi seçeneği olarak kullanılması zorunlu olmakla beraber enfeksiyon ve malignite riskini artırması ve bazı hastalarda primer veya sekonder cevapsızlık gelişmesi, bu ajanların uzun dönem kullanılmasını sınırlamaktadır (3).

Iletişim: Ayça Gökçen DEĞiRMENCI SALTÜRK

Haydarpaşa Numune Eğitim ve Araştırma Hastanesi Gastroenteroloji Kliniği Tıbbiye Caddesi, Üsküdar/İstanbul

E-mail: aycasalturk@gmail.com
Background and Aims: Vedolizumab is an $\alpha 4 \beta 7$ integrin used in the treatment of moderate-to-severe inflammatory bowel disease. It is preferred in patients with tumor necrosis factor antagonist experience. In our study, we evaluated the efficiency and safety of vedolizumab treatment at 12 months in complicated groups who were unresponsive to tumor necrosis factor antagonist treatment. Materials and Method: Patients admitted to the Haydarpaşa Numune Training and Research Hospital Gastroenterology Clinic between January 2019 and September 2020 were included in the study. The patients had been receiving vedolizumab treatment for more than 6 months. Seventeen (48.5\%) patients were female. Results: Endoscopic remission was achieved in 15 (65.2\%) patients with Crohn's disease, whereas 8 (34.78\%) patients were considered unresponsive. Endoscopic remission was recorded before vedolizumab treatment and after 12 months. The mean age was $43 \pm 13(22-76)$ years. A total of 23 patients had Crohn's disease and 12 patients had ulcerative colitis. In ulcerative colitis, the number of endoscopic remission and unresponsive patients were equal ( $n=6.50 \%)$. Conclusion: In our study, it was observed that the use of vedolizumab in patients with tumor necrosis factor antagonist experience was effective and safe.

Keywords: Crohn disease, ulcerative colitis, vedolizumab

Vedolizumab, orta ve ağır aktiviteli IBH tedavisinde kullanılan humanize edilmiş bir immünglobulin G1 monoklonal antikor olup alpha-4-beta-7 ( $\alpha 4 \beta 7)$ integrin heterodimeridir (4). Bu etkiyi, $\alpha 4 \beta 7$ integrin-pozitif inflamatuvar hücrelerin barsak dokusuna geçişini inhibe ederek ortaya çıkarır. $\alpha 4 \beta 7$ integrinin endotel hücrelerinde açığa çıkan mukozasal adresin hücre adhezyon molekül-1 (MAdCAM-1) ile etkileşimini bloke ederek gösterir $(5,6)$. MAdCAM-1 gastrointestinal traktan eksprese edilir ve primer olarak inflamatuvar hücrelerin barsağa migrasyonunu engeller, bu da sistemik etki yapan TNF antagonisti ilaçların yarattığı yan etki profilinden farklı olmasını sağlamaktadır (7). IBH'larında vedolizumabın indüksiyon ve remisyon devamlılığında etkinliği GEMINı 1-2 $(8,9)$ çalışmalarında

Değirmenci Saltürk AG. Vedolizumab experience in patients with inflammatory bowel disease: Single center data. The Turkish Journal of Academic Gastroenterology 2021;20:169-173. DOI: 10.17941/agd.1005038

Geliş Tarihi: 22.10.2021 • Kabul Tarihi: 27.10.2021 
ve uzun dönem etkinlik devamı ve güvenliği GEMINI-LTS çalışmalarında gösterilmiştir $(10,11)$. Ancak randomize kontrollü çalışmalar katı dahil edilme kriterleri ve seçilmiş homojen hasta grupları üzerinde yapılmakta olup, gerçek yaşam verilerini yansıtmayabilmektedir.

Çalışmamızda gerçek hayat verileri ile TNF antagonistine cevapsız, komplike hasta gruplarında tek merkez verileriyle vedolizumab tedavisinin 12 . aydaki etkinliğini ve güvenirliğini araştırdık.

\section{GEREÇ ve YÖNTEM}

Çalışmamız; Haydarpaşa Numune Hastanesi Gastroenteroloji Kliniği'ne başvuran klinik, endoskopik, radyolojik olarak tanı konmuş, orta veya ağır CH ve ÜK hastalarda yapılmış, kontrolsüz, retrospektif bir çalışmadır. Çalışmamız için Haydarpaşa Numune Eğitim ve Araştırma Hastanesi yerel etik kurulundan onay alınmıştır (23.02.2021 tarih ve E-62977267-903.99 sayı).

Ocak 2019- Eylül 2020 tarihleri arasında 6 aydan uzun süre vedolizumab tedavisi alan TNF antagonist deneyimli 18 yaş üzeri hastalar çalışmaya dahil edilmiştir. Hastaların yaş, cinsiyet, ko-morbid hastalıkları, sigara kullanımı, hastalık tipi ve süresi kaydedilmiştir. IBH tedavisinde kullandıkları ilaçlar (azatiopürin kullanımı, vedolizumab tedavisi öncesinde kullanılan TNF antagonisti ilaçlar), vedolizumab tedavisine başlanmadan önce ve ilaç başlandıktan sonra yapılan kontrol endoskopik aktivite skor kayıtları hastanemizin elektronik sisteminden elde edilmiştir. Çalışmanın COVID-19 pandemi dönemine denk gelmesinden ve retrospektif olmasından dolayı kayıtlar yeterli tutulamamıs, başlangıç klinik aktivite skorlarına ve C-reaktif protein (CRP) gibi inflamatuvar belirteçlere tüm hastalarda ulaşılamamışır.

Tek veya iki ardışık TNF antagonist tedavisine yanıtsız orta ve şiddetli $\mathrm{CH}$ veya ÜK hastalarında vedolizumab tedavisine başlanmıştır. Vedolizumab tedavisi 0-2-6. haftalarda ve sonrasında tedavi cevabına göre 4 veya 8 haftada bir gastroenteroloji servisinde IV 300 mg olarak uygulanmıştır. Tedavi başlangııından sonraki 6 aylık periyod içerisinde fistül gelişen veya operasyon geçiren hastalar çalışmaya alınmamıştır.

Çalışmamızın istatiksel analizinde IBM SPSS Statistisc 23 kullanılmışıı. Tanımlayıı verilerden kategorik değer olanlar n ve yüzde, numerik değer olanlar ise standart derivasyon ve mean olarak verilmiştir.

\section{BULGULAR}

Ocak 2019-Eylül 2020 tarihleri arasında 6 aydan uzun süre vedolizumab tedavisi almış 35 IBH hastası çalışma- mıza dahil edildi. Tüm hastaların 17'si (\%48.5) kadındı. Yaş ortalaması $43 \pm 13^{\prime}$ tü (22-76). Bu hastalardan 23'ü $\mathrm{CH}$ ve 12 'si ÜK hastasıydı. Tedavi başlangııında ilk 6 aylık dönem tedavi cevapsız hastalar (primer cevapsızlık-fistül gelişimi-opere olan hastalar) ve yan etki gelişiminden dolayı tedaviden çıkarılan hastalar çalışmaya dahil edilmedi. Hastalar değerlendirilirken $\mathrm{CH}$ ve ÜK hastalığı olarak 2 alt grupta toplandı. Hastaların demografik bulguları, klinik özellikleri ve endoskopik skorları Tablo 1'de gösterilmiştir.

$\mathrm{CH}$ için endoskopik remisyon; SES-CD'nin $\leq 4$ olması, ÜK hastalarında ise Mayo skorunun 0-1 olması kabul edildi. Opere edilmiş CH ise Rutgeerts' skoru 0-1 endoskopik remisyon olarak kabul edildi. Mukozasal iyileşme ise ülser olmaması olarak tanımlandı. Illk infüzyondan sonra 12 ayını tamamlamış hastalarda endoskopik remisyon değerlendirildi. COViD-19 pandemisi olmasından dolayı bazı hastaların 12. ay endoskopik kontrolü yapılamayıp bu süre 2-4 ay kadar uzatılabildi. CH hastalarının $15^{\prime}$ inde (\%65.2) endoskopik remisyon sağlanırken, 8 (\%34.78) hasta cevapsız kabul edildi. ÜK hastalarında ise endoskopik remisyon ve cevapsız hasta sayısı eşitti $(n=6, \% 50)$.

Hastaların vedolizumab öncesi kullandıkları biyolojik ajanlar karşılaşıtııldığında, remisyon sağlanan $15 \mathrm{CH}$ hastasının; 8'inde (\%22.9) sadece infliksimab (IFX), 3'ünde (\%8.6) sadece adalimumab (ADA), 4 (\%11.4) hastada ise iki biyolojik ajanın kullanıldığı görüldü. Cevapsız hastalarda ise 1 (\%2.9) hastanın IFX, 3 (\%8.6) hastanın ADA ve her iki biyolojik ajanın kullanıldığı 4 (\%11.4) hasta izlendi. ÜK hastalarını incelediğimizde ise remisyon grubu ile cevapsız grubun birbirine eşit olduğu gözlendi (IFX grubu $n$ $=3$ (\%8.6), ADA grubu $n=1$ (\%2.9), IFX \& ADA grubu $\mathrm{n}=2$ (\%5.7). Bu hasta grupları Tablo 2'de gösterilmiştir.

Bir ÜK ve bir CH hastası kısmi cevaplı oldukları için tedavileri 8 haftadan 4 haftaya çekildi. İi hastada da 12. ayın sonunda endoskopik remisyon gelişti.

Yan etki profilimize baktığımızda ise, bir hastada 6. ay şiddetli artralji, bir hastada ise bulantı şikayeti olup her iki hastada da tedavi devamında şikayetler kayboldu. Bir hastada tedavinin 19. ayında larenks kanseri gelişti. Bir hastada ise tedavinin 7. ayında tüberküloz menenjiti gelişti. Bu hastaların tedavileri sonlandııılı.

\section{TARTIŞMA}

Çalışmamız, bir veya daha fazla TNF antagonisti deneyimli, 12 aydan uzun süre vedolizumab tedavisi almış hastalarda; demografik özellikler, klinik bulgular, endoskopik remisyon ve mukozal iyileşmeyi gösteren tek merkezli gerçek yaşam verilerinin araştıııdığı bir çalışmaydı. 12. ay kontrolünde endoskopik cevap CH'larının \%65.2'sinde (15/23), ÜK hastalarının ise \%50'sinde (6/12) görüldü. 


\section{Tablo 1. Çalışmadaki ÜK ve CH hastalarının demografik bulguları ve klinik özellikleri; n (\%)}

\begin{tabular}{|c|c|c|}
\hline & $\mathrm{CH}$ & ÜK \\
\hline Kadın, n (\%) & $11(47.8)$ & $6(50)$ \\
\hline Yaş, (ort) & 46 & 37 \\
\hline Ko-morbid hastalık, n (\%) & $5(21.7)$ & $4(33.3)$ \\
\hline Sigara, aktif içici, n (\%) & $7(30.4)$ & $0(0)$ \\
\hline \multicolumn{3}{|l|}{ Montreal sınıflamasına göre lokalizyon } \\
\hline L1 (ileal): L2 (kolonik): L3 (ileokolonik) n (\%) & 9 (39): 5 (21): 9 (39) & \\
\hline \multicolumn{3}{|l|}{ Hastalık yaşı } \\
\hline A1 (< 16 yll): A2 (17-40 yıl): A3 (> 40 yıl) & $2: 16: 3$ & \\
\hline \multicolumn{3}{|l|}{ ÜK sınıflaması (Montreal) } \\
\hline E1 (rektit): E2 (distal kolit): E3 (pankolit) & & 0: $1(8.3): 11(91.6)$ \\
\hline \multicolumn{3}{|l|}{ Vedolizumab tedavisi öncesi kolonoskopi } \\
\hline Mayo skor 1: 2: 3 & & $0: 0: 12(100)$ \\
\hline Inflamasyon & $17(73.9)$ & \\
\hline Stenoz & $6(26)$ & \\
\hline \multicolumn{3}{|l|}{ Vedolizumab öncesi anti-TNF kullanımı n (\%) } \\
\hline Adalimumab & $6(26)$ & $2(16.6)$ \\
\hline Infliksimab & $9(39.1)$ & $6(50)$ \\
\hline Infliksimab +adalimumab & $8(34.7)$ & $4(33.3)$ \\
\hline \multicolumn{3}{|l|}{ Azatiopirün kullanımı } \\
\hline Halen kullanan & 2 & 4 \\
\hline EBV negatif hiç başlanmamış & 7 & 1 \\
\hline Kesilmiş (yan etki/yanıtsızlık) & $5: 9$ & $2: 5$ \\
\hline \multicolumn{3}{|l|}{52 hafta vedolizumab kullanım sonrası } \\
\hline \multicolumn{3}{|l|}{ Endoskopik aktivite skoruna göre kontrol n (\%) } \\
\hline Remisyon & $15(65.2)$ & $6(50)$ \\
\hline Cevapsız & $8(34.78)$ & $6(50)$ \\
\hline
\end{tabular}

ÜK: Ülseratif kolit, CH: Crohn hastalığı, TNF: Tümör nekrozis faktör, EBV: Epstein-Barr virüs.

Tablo 2. Tedavi öncesinde kullanılan biyolojlk ajan ile tedavi sonrası remisyon-cevapsızlık oranı, n (\%)

\begin{tabular}{|cccccccc|}
\hline & \multicolumn{3}{c}{ Endoskopik Remisyon } & \multicolumn{3}{c|}{ Cevapsız } \\
\hline & & IFX & ADA & IFX\&ADA & IFX & ADA & IFX\&ADA \\
\hline \multirow{2}{*}{ Tanı } & $\mathrm{CHn}(\%)$ & $8(\% 22.9)$ & $3(\% 8.6)$ & $4(\% 11.4)$ & $1(\% 2.9)$ & $3(\% 8.6)$ & $4(\% 11.4)$ \\
& ÜKn (\%) & $3(\% 8.6)$ & $1(\% 2.9)$ & $2(\% 5.7)$ & $3(\% 8.6)$ & $1(\% 2.9)$ & $2(\% 5.7)$ \\
\hline
\end{tabular}

IFX: İnfliksimab; ADA: Adalimumab, ÜK: Ülseratif kolit, CH: Crohn hastalı̆ı.

GEMINI 1 ÜK ve GEMINI 2 CH'larında vedolizumab kullanımını değerlendirmek için yapılan ilk randomize, prospektif, çift-kör, plasebo kontrollü çalışmalardır. 6. ve 52. haftalarda (indüksiyon ve remisyon tedavisi) yapılan değerlendirmelerde; ÜK hastalarında 6. haftada klinik cevap ve remisyon oranları \%47.1 - \%16.9 iken, $\mathrm{CH}^{\prime}$ ında bu oran \%31.4 - \%14.5 olarak saptanmıştır. 52. haftada bu oran ÜK hastalarında \%56.6 - \%41.8 ve $\mathrm{CH}^{\prime} ı$ nda ise \%39.0 - \%43.5 bulunmuştur $(8,9)$. GEMINI çalışması uzun dönem verilerinde ise, indüksiyon tedavisinde cevap alınan ÜK hastalarında çalışma 104. haftaya uzatıldığında remisyon oranının \%88'e, 152 . haftada ise \%96'ya çıktığı gözlenmiştir (10). 6. haftada indüksiyon tedavisine cevap veren GEMINI 2 hasta grubunda ise 104. haftada \%83, 152. haftada ise \%89 remisyon oranları elde edilmiştir (11). 
Bizim hasta grubumuzda $\mathrm{CH}^{\prime}$ larının endoskopik remisyon oranları ÜK hasta grubuna göre daha yüksek olarak saptanmıştı. Bu sonucun olası nedeni ise $\mathrm{CH}^{\prime}$ larında orta şiddetli aktivitesi olan hasta sayısı daha fazlayken, ÜK hasta grubunda ağır şiddetli aktivitesi olan hastaların yoğunlukta olmasıydı. Crohn hastalarında erken dönem biyolojik ajan kullanımı planlanırken, ÜK hastalarında konvansiyonel tedaviden biyolojik ajanlara geçiş daha geç olmaktadır.

Fransa GETAID grubunun gerçek yaşam verilerini yayınladıkları kohort çalışmasında; TNF antagonist deneyimli orta-şiddetli İBH olan 294 hasta üzerinden yapılan prospektif çalışmada 6 . ve 54. haftalar değerlendirilmiştir. 6. haftada ÜK hastalarında \%32, CH'larında ise \%31 klinik remisyon sağlandığı gözlenmiş̧tir. 54. haftada ise klinik remisyon oranı ÜK hastalarında \%40, $\mathrm{CH}^{\prime}$ larında ise \%27.2 bulunmuştur. Mukozal iyileşme ise ÜK'te \%54.8, $\mathrm{CH}^{\prime}$ nda ise \%29.8 olarak belirtilmiştir (12).

İsveç grubunun (SWIBREG) yaptığı geniş, prospektif kohort çalışmada 52. haftada ÜK ve CH hastalarında klinik remisyon oranı \%64 - \%60 olarak rapor edilmiştir. Bu hastaların \%86'sı TNF antagonisti deneyimlidir (13). Bizim çaıışmamıza en yakın veriler bu çalışmada saptanmışır.

İsrail grubunun gerçek yaşam verilerine bakıldığında; 52 . hafta cevabı CH'larında 62/133 (\%46.7), ÜK hastalarında ise 27/60 (\%45) olarak saptanmıştır (14).

Vivo ve ark.nın 102 hasta ile yaptığı prospektif çalışmada; ÜK hastalarında 14. haftada \%55 oranında klinik remisyon sağlanmış, mukozasal iyileşme ve klinik remisyon oranları ise 22. haftada ÜK hastalarında \%69 - \%76 iken CH'larında bu oran \%30 - \%52 olarak bulunmuştur (15).

Amerika'nın çok merkezli, kohort çalışması olan ve gerçek yaşam verilerini yansıtan VICTORY çalışmasında ise 52. haftada $\mathrm{CH}^{\prime}$ larında klinik remisyon \%35, mukozasal iyileşme $\% 63$, derin remisyon ise $\% 26$ olarak elde edilmiştir (16). \%71 TNF antagonisti deneyimi olan ÜK hastalarında 12 ay değerlendirilmesinde klinik remisyon $\% 51$, endoskopik remisyon ise $\% 41$ iken, $\% 14$ ile derin remisyon saptanmıştır (17). Yapılan çalışmalarda TNF antagonisti naive ve deneyimli hastalar karşılaştııılmış ve naive hastalarda daha yüksek düzeyde remisyon sağlandığı belirtilmiştir. Bizim çalışmamızda ülkemizin sağlık sistemi naive hastalarda vedolizumab kullanımına -birinci biyolo-

\section{KAYNAKLAR}

1. Peyrin-Biroulet L, Sandborn W, Sands BE et al. Selecting therapeutic targets in inflammatory bowel disease (STRIDE): Determining therapeutic goals for treat-to-target. Am J Gastroenterol 2015;110:1324-38. jik ajan olarak- izin vermediği için biz çalışmamızda böyle bir karşılaştırma yapamadık.

Colombel ve ark. vedolizumab güvenilirliği ile ilgili yapmış oldukları çalışmada vedolizumabın ciddi veya fırsatçı enfeksiyon riskini artırmadığını göstermiştir. Ayrıca malignite riski 0.1/100 insan-yllı olarak belirtilmiştir. Toplamda 18 hastada malignite saptanmış olup sıklıkla gastrointestinal maligniteler tespit edilmiştir. $\geq 20$ infüzyon dozu almış olan hastalarda ise daha sıklıkla gastrointestinal sistem dışında maligniteler bulunmuştur (18). Bizim vaka grubumuzda 1 hastada 19. ayda larenks kanseri geliştiği saptandı.

Siew ve ark. tarafından vedolizumab tedavisi alan hastalarda fırsatçı enfeksiyon ve tüberküloz gelişme sıklığının değerlendirildiği literatürde toplam 5 hastada tüberküloz (2 hastada latent tüberküloz, 3 hastada pulmoner tüberküloz) saptanmış ve bu hastaların hepsinin endemik bölgelerde yaşadıkları belirtilmiştir (0.1/100 insan ylı). Illk infüzyondan ortalama 105 gün sonra (46-938 gün) tanıları konmuş olduğu saptanmışı̧ı (19). Bizim vaka grubumuzda infliksimab tedavisi öncesi izoniyazid profilaksisi almış olan ÜK hastamızda vedolizumab tedavisinin 7. ayında tüberküloz menenjiti gelişti.

Bizim çalışmamızda bazı eksik noktalar bulunmaktaydı. Retrospektif olarak tasarlanan çalışmada başlangıç klinik aktivite skorları kayıt edilmediği için hastalık başlangıcı değerlerine ulaşılamadı. Raporlu ilaçların COViD-19 pandemisinden dolayı poliklinik başvurusu olmadan eczaneden temin edilebilmesinden dolayı hastaların takibi yeterince yapılamayıp, kontrol klinik aktivite skorları ve CRP gibi inflamatuvar belirteçlerine ulaşılamadı. Bundan dolayı klinik remisyonları değerlendirilemedi.

Sonuç olarak çalışmamızda, TNF antagonisti deneyimli hastalarda, özellikle $\mathrm{CH}^{\prime}$ ları olmak üzere İBH hastalarında vedolizumab kullanımının etkin ve güvenilir olduğu gözlemlenmiştir.

Etik Kurul: Bu çalışma için Haydarpaşa Numune Eğitim ve Araştırma Hastanesi yerel etik kurulundan onay alınmıştır (23.02.2021 tarih ve E-62977267-903.99 sayı).

Çıkar Çatışması: Yazar herhangi bir çıkar çatışması olmadığını kabul eder.

Finans: Yazar bu makale için herhangi bir finansal destek beyan etmemistir.

2. Kozuch PL, Hanauer SB. Treatment of inflammatory bowel disease: A review of medical therapy. World J Gastroenterol 2008;14:35477. 
3. Annese V, Duricova D, Gower-Rousseau C, Jess T, Langholz E. Impact of new treatments on hospitalisation, surgery, infection, and mortality in IBD: A focus paper by the epidemiology committee of ECCO. J Crohns Colitis 2016;10:216-25.

4. Garnock-Jones KP. Vedolizumab: a review of its use in adult patients with moderately to severely active ulcerative colitis or Crohn's disease. BioDrugs 2015;29:57-67.

5. Fedyk ER, Wyant T, Yang LL, et al. Exclusive antagonism of the $\alpha 4 \beta 7$ integrin by vedolizumab confirms the gut-selectivity of this pathway in primates. Inflamm Bowel Dis 2012;18:2107-19.

6. Soler D, Chapman T, Yang LL, et al. The binding specificity and selective antagonism of vedolizumab, an anti-alpha4beta7 integrin therapeutic antibody in development for inflammatory bowel diseases. J Pharmacol Exp Ther 2009;330:864-75.

7. Hesterberg PE, Winsor-Hines D, Briskin MJ, et al. Rapid resolution of chronic colitis in the cotton-top tamarin with an antibody to a gut-homing integrin alpha 4 beta 7. Gastroenterology 1996;111:1373-80.

8. Sandborn WJ, Feagan BG, Rutgeerts $P$, et al; GEMINI 2 Study Group. Vedolizumab as induction and maintenance therapy for Crohn's disease. N Engl J Med 2013;369:711-21.

9. Feagan BG, Rutgeerts P, Sands BE, et al; GEMINI 1 Study Group. Vedolizumab as induction and maintenance therapy for ulcerative colitis. N Engl J Med 2013;369:699-710.

10. Loftus EV Jr, Colombel JF, Feagan BG, et al. Long-term efficacy of vedolizumab for ulcerative colitis. J Crohns Colitis 2017;11:400-11.

11. Vermeire S, Loftus EV Jr, Colombel JF, et al. Long-term efficacy of vedolizumab for Crohn's disease. J Crohns Colitis. 2017;11:412-24
12. Amiot $A$, Serrero $M$, Peyrin-Biroulet $L$, et al; OBSERV-IBD study group and the GETAID. One-year effectiveness and safety of vedolizumab therapy for inflammatory bowel disease: a prospective multicentre cohort study. Aliment Pharmacol Ther 2017;46:310-21

13. Eriksson C, Marsal J, Bergemalm D, et al; SWIBREG Vedolizumab Study Group. Long-term effectiveness of vedolizumab in inflammatory bowel disease: a national study based on the Swedish National Quality Registry for Inflammatory Bowel Disease (SWIBREG). Scand J Gastroenterol 2017;52:722-9.

14. Kopylov U, Avni-Biron I, Ron Y, et al. Effectiveness and safety of vedolizumab for maintenance treatment in inflammatory bowel disease-The Israeli real world experience. Dig Liver Dis 2018;51:6874.

15. Vivio EE, Kanuri N, Gilbertsen JJ, et al. Vedolizumab effectiveness and safety over the first year of use in an IBD clinical practice. J Crohns Colitis 2016;10:402-9.

16. Dulai PS, Singh $S$, Jiang $X$ et al. The real world effectiveness and safety of vedolizumab for moderate-severe Crohn's disease: Results from the US VICTORY Consortium. Am I Gastroenterol 2016;111:1147-55.

17. Narula N, Peerani F, Meserve J, et al. Vedolizumab for ulcerative colitis: Treatment outcomes from the VICTORY Consortium. Am J Gastroenterol 2018;113:1345.

18. Colombel JF, Sands BE, Rutgeerts P, et al. The safety of vedolizumab for ulcerative colitis and Crohn's disease. Gut 2017;66:839-51.

19. Ng SC, Hilmi IN, Blake A, et al. Low frequency of opportunistic infections in patients receiving vedolizumab in clinical trials and post-marketing setting. Inflamm Bowel Dis 2018;24:2431-41. 